\title{
Effects of administration of probiotic strains on GALT of larval gilthead seabream: Immunohistochemical and ultrastructural studies
}

\author{
Simona Picchietti ${ }^{\text {a }}$, Massimo Mazzini ${ }^{\text {a }}$, Anna Rita Taddei ${ }^{\mathrm{b}}$, Raffaella Renna ${ }^{\mathrm{a}}$, \\ Anna Maria Fausto ${ }^{a}$, Victoriano Mulero ${ }^{c}$, Oliana Carnevali ${ }^{\mathrm{d}}$, \\ Alberto Cresci ${ }^{\mathrm{e}}$, Luigi Abelli ${ }^{\mathrm{f}, *}$ \\ ${ }^{a}$ Dipartimento Scienze Ambientali, Università della Tuscia, 01100 Viterbo, Italy \\ ${ }^{\mathrm{b}}$ Centro Interdipartimentale Microscopia Elettronica, Università della Tuscia, 01100 Viterbo, Italy \\ ${ }^{\mathrm{c}}$ Department Cell Biology, University of Murcia, 30100 Murcia, Spain \\ ${ }^{\mathrm{d}}$ Dipartimento Scienze del mare, Università Politecnica delle Marche, 60100 Ancona, Italy \\ ${ }^{\mathrm{e}}$ Dipartimento Scienze Morfologiche e Biochimiche Comparate, Università di Camerino, Italy \\ ${ }^{\mathrm{f}}$ Dipartimento Biologia, Sezione Anatomia Comparata, Università di Ferrara, Via Borsari 46, 44100 Ferrara, Italy
}

Received 12 December 2005; revised 16 January 2006; accepted 14 March 2006

Available online 28 March 2006

\begin{abstract}
Two bacterial strains Lactobacillus fructivorans (AS17B), isolated from adult seabream (Sparus aurata L.) gut, and Lactobacillus plantarum (906), isolated from human faeces, were administered contemporaneously during seabream development using Brachionus plicatilis and/or Artemia salina and dry feed as vectors.

Experimental group A received the probiotic strains already via rotifers from day 5 post-hatch (ph), whereas treatment of group B began with Artemia feeding from day 27 ph. Fish were sampled at day 28 ph (group A and control) and day 99 ph (groups A, B and control) for electron microscopy, histology and immunohistochemistry with the polyclonal antiserum ORa against homologous serum Ig and the mAb G7 specific for seabream acidophilic granulocytes. In all groups, timing and pattern of differentiation of the digestive tract did not differ. Furthermore, neither tissue damage nor manifest inflammation was provoked by probiotic administration.

At day 28 ph, the developing GALT already housed mucosal leucocytes, including $\mathrm{Ig}^{+}$cells but no acidophilic granulocytes. No differences were seen between experimental groups.

At day $99 \mathrm{ph}$, the density of $\mathrm{Ig}^{+}$cells $(+51 \%)$ and acidophilic granulocytes $(+284 \%)$ was significantly higher $(p<0.05)$ in group A than in controls. Also group B had a higher density of $\mathrm{Ig}^{+}$cells $(+17 \%)$ and acidophilic granulocytes $(+130 \%)$ compared with controls, although less pronounced. Light and electron microscopy observations detailed the occurrence of heterogeneous populations of lymphocytes and granulocytes in the developing intestinal mucosa, and highlighted the net expansion of G7 ${ }^{+}$acidophilic granulocytes $(\mathrm{A}+536 \%$, B $+292 \%$ vs. control) due to probiotic administration.
\end{abstract}

Abbreviations: GALT, gut-associated lymphoid tissue; IEL, intraepithelial lymphocyte; IHC, immunohistochemistry; IR, immunoreactive; mAb, monoclonal antibody; MGG, May-Grünwald-Giemsa; Lp, lamina propria; PBS, phosphate-buffered saline.

* Corresponding author. Fax: +39 0532291715.

E-mail address: abl@unife.it (L. Abelli). 